\title{
Determinants of Defined Contribution Plan Deferral
}

\section{Postprint}

For published article see:

Yao, R., Ying, J., \& Micheas, L. (2013). Determinants of defined contribution plan deferral. Family and Consumer Sciences Research Journal, 42(1), 55-76.

\begin{abstract}
The purpose of this study was to examine the trend of Defined Contribution (DC) plan deferral before and after the Great Recession. The investment principle of "buying when prices are low" suggests that DC plan deferral should increase during years when portfolio returns are low. The dependent variable was the dollar amount of elective deferral expressed as a percentage of the maximum amount allowed by the Internal Revenue Service. The sample consisted of eligible DC plan participants in the 2004, 2007, and 2010 Survey of Consumer Finances (SCF). The descriptive statistics showed that in 2004 and 2007, about half of respondents deferred less than $20 \%$, about a quarter deferred between 20 and $40 \%$, and only a little more than $7 \%$ maximized their DC plan deferral. However, the deferral rates dropped dramatically in 2010. The results of ordered logistic regression showed that respondents who: had more education, were in excellent health, with more income, willing to take investment risk, were allowed to borrow from the DC plan, were allowed to withdraw from the DC plan, and were homeowners without a mortgage were more likely to make a larger deferral to the DC plan. However, the most important implication from the study is that so many respondents were not participating fully in 2004 and 2007 and that percentages for DC plan deferrals were even lower in 2010. Educators,
\end{abstract}


employers, and financial advisors should help workers understand the importance of participating fully or to the extent possible in DC plan contributions.

Keywords: behavioral economics, decision making, defined contribution plan deferral, Survey of Consumer Finances 


\section{Introduction}

Most of today's retirees' income is funded by three major sources: Social Security, private pension plans, and individual savings. Most of today's retired individuals currently receive income support from Social Security. Some retirees currently receive monthly payments from defined benefit (DB) plans. However, these two major sources of retirement income have changed over time. The combined Social Security trust funds are projected to become exhausted in 2036 (Social Security Board of Trustees, 2011), which implies a potential reduction in Social Security benefits that future retirees would receive. Unlike DB plan participants, individuals who are eligible to participate in a DC plan must decide whether they will participate, how much they will contribute, and how the contributions will be invested. Also, employers have increasingly shifted from DB plans to DC plans. The total number of private DB plans was 103,346 in 1975 and 46,543 in 2010; and the total number of private defined contribution (DC) plans was 207,748 in 1975 and 654,469 in 2010 (Department of Labor, 2012).

Besides the changes in Social Security and the trend of DC plans becoming a more dominant type of pension plan, individual's longevity risk keeps challenging the success of retirement preparation. Life expectation at birth for the total population increased from 70.8 (67.1 for males and 74.7 for females) in 1970 to 78.0 (75.5 for males and 80.5 for females) in 2008 (U.S. National Center for Health Statistics, 2012). The current workforce should be aware that retirement savings will have a direct and significant impact on their retirement wealth accumulation and, consequently, the longevity of their retirement income. Studies are needed to examine the savings behavior of eligible DC plan participants who are more responsible for their retirement preparation than DB plan participants. 
Economic theories assume individuals are completely informed and rational when making decisions. "Buy low" is an incredibly simple concept during the saving stage of retirement, yet it is difficult to follow through. Both astute and naive individual investors may behave in ways contrary to what theories would suggest (Ciccone, 2011; Statman, Thorley, \& Vorkink, 2006). Some investors decided to move to cash when their investment portfolio experienced large decreases during the Great Recession (Yao, 2011). Some reduce or even refrain from their DC plan deferral during a down market (e.g. Butrica \& Smith, 2012; Utkus \& Young, 2011). If the decline in the rate and degree of participation was not induced by a change in employment or necessary consumption needs, reducing and refraining from their DC plan participation was a deviation from what rational individuals would do. Those individuals not only missed the opportunity of buying low but also fell behind in their retirement wealth accumulation. This behavior could bring about serious economic consequences, such as inadequate retirement income.

Investors may have a target amount for satisfactory retirement wealth and decide to retire when that amount is reached (Schleef \& Eisinger, 2007). When market returns are lower, individuals saving for retirement should save more to stay on track toward adequately funding their DC plan. Due to the compounding nature of returns, even a small decrease in current contributions will result in a large decrease in the DC plan balance at retirement. Reducing the DC plan deferral causes people to miss the opportunity to buy low, and most importantly, is inconsistent with people's retirement saving goal.

Since the Great Recession, the future financial outlook at retirement for today's workforce has remained questionable. Among today's pre-retired households, $44 \%$ will be unable to maintain $70 \%$ of their permanent income in retirement (Yuh, 2011). Facing both the 
aforementioned exogenous changes in two of the three major sources of retirement income and the endogenous longevity increase, individuals eligible for DC plans cannot afford to make retirement saving mistakes. This study will use a national public dataset to examine the trend of the DC plan deferral over time. This study will also explore factors related to plan deferral by eligible participants as a first step toward the solution for the retirement savings adequacy challenge. Results of this study will provide information to researchers, financial professionals, employers and policy makers on DC plan participants' behavior in different economic environments so they can use it to better facilitate the general public's retirement preparation.

\section{Literature Review}

The shift from Defined Benefit pension plans (DB plans) to Defined Contribution retirement savings plans (DC plans) over the past three decades is well documented (Dushi \& Iams 2008; Munnell \& Sundén, 2004; Wiatrowski, 2004). As a result of this shift, employees became exposed to investment and longevity risks, which include the possibility of accumulating an inadequate amount of retirement wealth and the possibility of outliving their retirement income. Although eligible employees are usually enrolled in DB plans by employers without having to make an election, most DC plans require employees to opt-in to a DC plan and choose the degree of their participation. Consequently, DC plan participants have greater responsibilities than typical DB plan participating employees to manage their contributions in order to secure their own retirement benefits. The shift from DB to DC plans has led to important changes in the distribution of employees participating in retirement plans and, specifically, DC plans. 
Interests in exploring how the shift from DB to DC plans affects employees across different demographic and socio-economic populations are on the rise (Huberman, Iyengar, \& Jiang, 2007). Empirical research has shown that DC plan participants' contributions are mainly determined by their demographic characteristics, financial condition, employment status, and psychological factors.

\section{Age, Cohort and Period Effect}

Several studies found a positive relationship between age and employee's contribution to DC plan (Hastings \& Mitchell, 2011; Holden \& VanDerhei, 2001; Huberman et al. 2007; Papke, 2003). Honig and Dushi (2009) found the overall participation in tax-deferred retirement plans increased during the period of 1984 to 2003. Their findings also pointed out a cohort effect on pension plan participation rate. Younger cohorts (War Babies born 1942-1947 and Early Baby Boomers born 1948-1953) were more likely to participate in such plans than the HRS cohort (born 1931-1941) of the same ages, although their contributions as a percent of earnings were not significantly larger. Findings from analysis of Social Security administrative data confirmed that participation in tax-deferred retirement plans increased over time (Cunningham \& Engelhardt, 2002; Pattison \& Waldron, 2008). Combining the Social Security administrative data and the HRS data, Cunningham and Engelhardt (2002) also showed an increase over time of contributions to $401(\mathrm{k})$ plans as a percentage of earnings.

\section{The Effect of Demographic Characteristics on Employee Contributions to DC Plans}

Compared with males, females had a lower ratio of individual DC pension wealth to total wealth (Bajtelsmit, Bernasek, \& Jianakoplos, 1999). Huberman et al. (2007) discovered that compared with males, females were not only more likely to participate in DC plans but also contributed a higher dollar amount. Bajtelsmit et al. (1999) pointed out that single people have a 
smaller proportion of wealth held in DC pensions than married couples. However, Xiao (1997) concluded that married people's 401(k) plan contributions are less than single people's. Hastings and Mitchell (2011) found the relationship between marital status and DC plan contributions to be vague. One reason for this vagueness may be that marital status and gender affect the contribution simultaneously. Depending on who was the respondent in a married couple household, the individual contribution could be different. Papke (2003) combined gender and marital status into one variable. Results showed that compared with married males, single females and married females contributed a higher percentage of salary to their DC plan.

Evidence showed the more educated people were, the higher their tendency to participate in DC plans (Bassett, Fleming, \& Rodrigues, 1998; DeVaney \& Zhang; 2001; Joo \& Grable, 2005). Conversely, Papke (2003) found that education negatively affected respondents' deferral rate to DC plans. Joo and Grable (2005) showed whites had a higher likelihood to have a retirement saving program than all other races as a group. Yuh and DeVaney (1996) found that black and Hispanic couples contribute less to their DC accounts than couples of other races.

\section{The Effect of Employee's Financial Conditions on Contributions to DC Plans}

People with higher income were found to be more likely to save in retirement accounts (Bassett et al. 1998; Dushi, Iams, \& Tamborini, 2011; Hastings \& Mitchell, 2011; Joo \& Grable, 2005) and to have contributed a higher percentage of income to DC plans (DeVaney \& Zhang, 2001; Dushi et al. 2011; Huberman et al. 2007; Papke, 2003). On the other side, Xiao (1997) found the family head's labor income has a significant positive relationship with DC contribution amount and slightly negative relationship with the DC contribution as a percentage of salary. Holden and VanDerhei (2001) found the share of salary contributed to 401(k) plans increased as income increased until $\$ 80,000$, where the percentage started to decrease as income increased. 
This decrease may be related to the definition of contribution. Since the Internal Revenue Service (IRS) imposes limits on the maximum contribution amounts, it is not surprising to find higher income participants contribute a smaller percentage.

Wealth or net worth was also usually studied in past research on retirement savings behavior. Papke (2003) found that net worth positively affected the percentage of salary contributed to DC plans. Huberman et al. (2007) showed that wealth had a positive effect on both DC participation and contribution. Bajtelsmit et al. (1999) showed that women with more wealth hold a lower proportion of wealth in DC pension accounts; however, men do the opposite.

While different conclusions were made, home ownership was always included as an explanatory variable in past research on retirement savings. Compared with renters, homeowners were more likely to participate in DC plans (Bassett et al. 1998) and they also contributed more to DC pensions (Yuh \& DeVaney, 1996). However, Bajtelsmit et al. (1999) pointed out that men's DC contribution was not significantly affected by home ownership, but women's DC contribution had a significantly negative relationship with home ownership.

\section{The Effect of Job Tenure and Features of Respondent's Pension Plans}

Retirement benefits are normally thought to be closely connected with one's job tenure (i.e., the number of years working for the current employer). Empirical evidence showed that the longer job tenure increased the DC plan contribution amount (Bassett et al. 1998; Xiao, 1997; Yuh \& DeVaney, 1996). Results found by Holden and VanDerhei (2001) and Huberman et al. (2007) suggested that relatively longer tenure encouraged employees to participate in DC plans but decrease participation rates if tenure was over a certain length.

Evidence from past research studies suggested a positive relationship between employer match and employee's participation in DC plans (Engelhardt \& Kumar, 2007; Hassan \& 
Lawrence, 2001; Huberman et al. 2007; Xiao, 1997; Zhou, 2009). However, Holden and VanDerhei (2001) concluded the opposite. Kusko, Poterba and Wilcox (1994) and Bassett et al. (1998) found that contribution decisions of eligible employees were insensitive to the rate of employer's match. Bassett et al. (1998) also found participation rate increased if the employer provided a match. Papke (1992) concluded that participation should increase with the match rate and contributions would increase as well, but may eventually fall at higher match rates.

Pension plan ownership and plan features were also found to have affected DC plan participation and contribution. Yuh and DeVaney (1996) pointed out that having a DB plan negatively affected DC plan contribution amounts. Huberman et al. (2007) found that ownership of a DB plan did not significantly affect the decision to participate but positively affected the contribution as a percent of salary to DC plans. Empirical evidence also showed that DB plan ownership increased the percentage of salary contributed to DC plans (Papke; 2003) and having other pension plans decreased the likelihood of DC plan participation (Bassett et al. 1998). Holden and VanDerhei (2001) found 401(k) plan contribution rates were higher when plans allowed borrowing. Both contribution amount and contribution rate as a percentage of salary to 401(k) plans were higher when plans allowed emergency withdrawal (Xiao, 1997).

The Psychological Factors Affecting Employees' DC Contribution Behaviors

Empirical evidence showed that risk tolerance positively affected both the DC plan contribution amount (Xiao, 1997; Yuh \& DeVaney, 1996) and contribution rate as a percentage of income (Xiao, 1997). Having a motive to save for retirement positively affected the amount and rate of contribution to 401(k) plans (Xiao, 1997). Employees with proactive financial attitude were more likely to have a retirement saving program (Joo \& Grable, 2005).

\section{Contributions of This Study}


Previous studies of factors affecting employee's participation and contribution into DC pension plans had limitations. Several of the studies only studied the determinants of whether an employee participated in a DC plan or not (e.g. Bassett et al. 1998; Hassan \& Lawrence, 2001). Their results might not be used to adequately make further judgments about how those factors affect participant contribution level in DC plans. Granted, participation is the first step in saving for retirement, but it is the degree of contribution that determines how close people's retirement saving is on track.

Some studies did focus on the contribution rate or amount, but most of them only used data from one survey year (e.g. Bajtelsmit et al. 1999; Hassan \& Lawrence, 2001; Papke, 1992; Xiao, 1997; Yuh \& DeVaney, 1996). Those studies can only show the effect of various factors on contribution at one point in time. Using data from multiple survey years could help to analyze the effect of time-related factors on DC contribution.

Despite growing research and policy attention, studies using nationally representative data to examine variations in DC plan participation and contribution rates are relatively limited. One important issue not previously addressed is whether analyzing DC contribution behavior over a longer period would provide more insight into explanation of participants' DC contribution behavior than a short-term measure would. For example, a change in market returns may affect the performance of the retirement portfolio, which could, consequently, affect contributions to DC plans.

To address these limitations, this study will 1) focus on determinants of the size of employee's contribution; 2) use multiple survey years' data from Survey of Consumer Finances to conduct an age-period-cohort analysis; 3) include important variables discussed above to better understand and describe the change of employee's contribution to DC plans over time. 


\section{Conceptual Framework}

According to the Life Cycle Hypothesis (Ando \& Modigliani, 1963), individuals accumulate wealth when they work to finance consumption after retirement, when earned income stops. The following formulas explain this relationship:

$$
\begin{gathered}
W=\sum_{t=0}^{R-A} S_{t}\left(1+r_{t}\right)^{R-A-t} \\
N=\sum_{t=1}^{T-R} \frac{C-P}{\left(1+r_{t}\right)^{t}}
\end{gathered}
$$

where $W=$ accumulated wealth to support retirement

$N=$ wealth needed to support $\mathrm{t}$ retirement

$A=$ current age

$R=$ age at retirement

$T=$ age at death

$s_{t}=$ savings in year $t$

$r_{t}=$ expected portfolio real rate of return of year $t$

$C=$ desired consumption level at retirement, assumed to be constant

$P=$ expected income from Social Security and DB plans, assumed to be constant

The difference between the desired retirement consumption and the expected income from sources such as Social Security and DB plans (i.e. C - P) is contribution to DC plans and other personal savings. Individuals can retire when $W \geq N$.

The expected portfolio return of year $t\left(r_{t}\right)$ should be based on the systematic risk of the portfolio, which is determined by the portfolio asset allocation (Sharpe, 1964). When the returns are low, the accumulated retirement wealth $(W)$ reduces its size; therefore, investors should 
save/invest more (i.e., increase $s_{t}$ ) to make up for the difference. The simple "buy low" principle would also guide investors to do so. Similarly, when the returns are high, the accumulated retirement wealth $(W)$ increases in size, and investors can reduce savings/investments (i.e., decrease $s_{t}$ ) and still remain "on-track" for their retirement preparation. If DC plan participants behave in the fashion described above, it should be expected that: 1) in years when returns are lower than the prior year, eligible DC plan participants will increase their deferral amount (if not already maximized); and 2) in years when returns are higher than the prior year, eligible participants will not increase their deferral amount. They may contribute the same amount if they would like to achieve their retirement savings goal earlier or build up reserves for possible future declines in returns.

Public policies and the IRS adjustment of maximum deferral amounts over time affect DC participants' deferral via employers' matching practices (decision to match and the size of the match). These factors affect individuals' DC plan deferral behavior since it provides additional information and sets new constraints. Since 2006, employers have been encouraged to: 1) automatically enroll employees in the DC saving plan unless they explicitly choose to opt out; 2) make reasonably generous contributions to employee accounts; and 3) automatically increase participant contribution to the plan (Pension Protection Act of 2006). This development should lead to an increase in the employee take-up rate of DC plans in years after 2006. This development should also affect the deferral amount of participants. Because the employer's match and participants' deferral should be equal to the total necessary contribution into the DC plans, which is subject to an annual addition limit, the employer's match and the participants' deferral rate should have a negative relationship. Hypotheses 
Based on the conceptual framework, it is hypothesized that:

$\mathrm{H}_{1}$ : participants would defer a higher amount, in real terms, in years when their portfolio return is lower than other years;

$\mathrm{H}_{2}$ : participants whose employer matches their deferral would contribute a lower amount than those whose employer does not provide a match.

\section{Methodology}

Data

This study combined the 2004, 2007 and 2010 Survey of Consumer Finances (SCF) datasets to examine the period effect on DC plan participants' degree of plan deferral. This period covered both before and after the Pension Protection Act of 2006 and the Great Recession. The SCF is a survey conducted triennially and supported by the Board of Governors of the Federal Reserve System in cooperation with the Statistics of Income Division of the Internal Revenue Service. The survey provides information on households' financial conditions, especially their balance sheet information, perceptions of financial situations and demographic characteristics. The three survey years were selected for analyses because 1) the questionnaires related to DC plans for those three survey years were more consistent than previous years; and 2) market performance was very different during those periods, which allows investigation on how market performance was related to individuals' contribution to their DC plan.

Because the research was to examine contributions to DC plans, respondents who were ineligible for a DC plan through their current job(s) were excluded from the study. Also excluded from the analyses were respondents who were younger than 21 years of age or older than 70.5. Generally, employers require an employee to be at least 21 years old and to have a 
year of service with the company before the employee is eligible to participate in a DC plan. Although plans may allow employees to begin participation before reaching age 21, to ensure the sample respondents were all eligible, those who were younger than 21 were excluded. The 70.5 age limit was chosen because for some participants, the Required Minimum Distribution must begin once the participant turns age 70.5 , and he/she may not be able to contribute to his/her DC account(s). Plan participation after age 70.5 has some complications, depending on employment and ownership status. To ensure the entire sample was qualified to participate, respondents over age 70.5 were excluded from this study. After applying the sample selection criteria, the sample size was 1,033 for $2004,1,039$ for 2007 , and 1,430 for 2010 for a total sample size of 3,502.

\section{Dependent Variable}

The dependent variable was the rate of DC plan deferral. This rate was measured by the dollar amount of elective deferral as a percentage of the maximum amount allowable by the IRS. This maximum amount included both the general limit and the catch-up contribution limit of each year. Individuals who have 15 or more years of service with certain organizations (e.g. an educational organization, health and welfare service agency, church) are allowed to increase their DC plan deferrals by a certain amount (Internal Revenue Service, 2013). The maximum amount in this study did not take into account the 15 -year rule since the information provided by the SCF data was inadequate to determine whether the respondent was eligible to apply such a rule.

This measure of the deferral rate was different from previous studies that measured DC deferral by the dollar amount (in nominal dollars). Both the maximum limit for DC elective deferral and the catch-up contribution increased over time. The purpose of this type of increase is to adjust for inflation. It should not induce higher DC plan participation rates, nor should it affect the amount of deferral in real terms, although this adjustment is rigid and does not fully 
represent the effect of inflation. However, on the surface, this increase can encourage a higher deferral amount in nominal terms by DC plan participants who needed to save more for retirement outside of DC plans. Those who did not reach the maximum limit in prior years would not be induced to increase their nominal deferral amount. The advantage of the measure adopted in this study is that it takes out the increase's complication (deferral amount adjusted for inflation).

The measure of the deferral rate used in this study also differed from prior studies that measured DC deferral as a percentage of respondents' labor income or total income. This definition avoided the possible misinterpretation when a respondent made the maximum allowable contribution to his/her DC accounts but entered data analyses as having made a low rate of deferral due to a high level of labor income or total income.

The sample included eligible DC plan participants only. The proportion of actual zero contribution in each year was very small: $0.62 \%$ in $2004,0.28 \%$ in 2007 , and $0.31 \%$ in 2010 . The respondent's percent contribution to the DC plan was coded into six categories $(0-20 \%, 20$ $40 \%, 40-60 \%, 60-80 \%, 80-100 \%$, and $100 \%)$. There were two reasons for doing so: 1) the dependent variable displayed a significant departure from normality (bimodal), and 2) the distribution of the dependent variable was truncated (between $[0,1]$ ).

\section{Independent Variables}

Independent variables included five categories: 1) age, period, and cohort; 2)

demographic characteristics of the respondent; 3) ownership and feature of respondent's pension plans; 4) economic situations of the respondent and the household; and 5) respondent's expectations. The age, period and cohort variables were defined in a way to address the wellknown multicollinearity issue in the age-period-cohort (APC) analysis (Yang \& Land, 2006). 
Age was coded at 10-year increments: 21-30, 31-40, 41-50 (reference group), 51-60 and 61-70.5. Period was defined as the survey years (i.e., 2004, 2007 and 2010), with 2007 being the reference year. Cohort consisted of four widely recognized generations (Yao, Sharpe, \& Wang, 2011): the silent generation (born before 1946), the baby boomer generation (born 1946-1964, reference group), the X generation (born 1965-1980), and the Y generation (born after 1980).

Demographic characteristics included: household type, number of related children, respondent's education and race/ethnicity. Household type was defined based on respondent's gender and marital status and grouped as married male, married female (reference group), single male and single female. Married and living with partners were coded as "married," and single included never married, divorced and widowed. The number of children was defined as the number of related children to the respondent in the primary economic unit. Respondents' education levels were classified into five categories: less than a high school diploma, high school diploma (reference group), some college, bachelor's degree and graduate or professional degree. Race/ethnicity included: white (reference group), black, Hispanic and other.

Variables related to the ownership and features of respondent's pension plans included: DB plan ownership (1=have at least one DB plan; 0=have no DB plan), number of owned DC plans ( $1=$ have one plan; $0=$ have more than one plan), permission to borrow against DC plans ( $1=$ yes; $0=$ no), permission to withdraw from DC plans $(1=y e s ; 0=$ no), and employer's match $(1=$ employer matches; $0=$ no). Other economic characteristics included home ownership (renting, owning with loans [reference group], owning without loans), respondent's job tenure (years of service at current job), total annual household income (log-transformed), current household income in relationship to normal household income (current income more than normal income, current income equal to normal income and current income less than normal income 
[reference group]), and household net worth (in units of $\$ 100,000$ ). The lowest value of total annual household income was $\$ 0$. One dollar was added to all values of income before the logtransformation. Income and net worth were converted into 2010 dollars.

Expectations included respondents' risk tolerance level, expectation of large asset transfer (e.g. inheritance), expectation of future U.S. economic performance, overspending, having retirement as a saving motive, self-perceived retirement adequacy and self-perceived health condition. Risk tolerance level included four categories of willingness to take risks in exchange of returns: no risk, average risk (reference group), above average risk and substantial risk. Expectation of large asset transfer was coded as 1 for expecting to receive such asset transfer in the future and 0 for not. Expectation of future U.S. economic performance included three categories: better, worse (reference group), and about the same. Overspending and having retirement as a saving motive were both dichotomous variables with 1 being yes and 0 being no. Respondents' self-perceived adequacy for expected retirement income from Social Security and job pensions had five categories: totally inadequate, inadequate, enough to maintain standard of living (reference group), satisfactory, and very satisfactory. Respondents' self-perceived health condition was categorized as excellent health, good health (reference group), fair health and poor health.

\section{Method of Analysis}

The complexity of the SCF data arises from the sample design, multiple imputation of missing data, and issues related to confidentiality and disclosure (Montalto, 1998). The SCF uses weights to adjust for differential nonresponses (Bricker et al. 2012). Due to the confidentiality and disclosure concerns, standard methods of calculating sampling error cannot be used (Montalto, 1998). Instead, the SCF uses a bootstrap technique for computing estimates 
of sampling variance (Bricker at al., 2012). To address missing information on individual questions within the interview, the SCF uses statistical methods to impute missing data. This technique makes multiple estimates of missing data to allow for an estimate of the uncertainty attributable to this type of nonresponse (Bricker at al., 2012).

SCF is a standard, geographically based random sample and a special oversample of relatively wealthy families. Weights (X42001) are used to combine information from the two samples to make estimates for the full population and are recommended for use by the Federal Reserve. As mentioned earlier, the standard methods of calculating sampling error for complex surveys cannot be used without releasing sensitive information about primary sampling units and strata. Instead, the Federal Reserve provides 999 bootstrap replicate weights for SCF data users to obtain correct standard errors. These weights were used in the statistical analyses in this study.

In all three surveys, a consistent multiple imputation method was used by the SCF to provide the best possible estimate for each missing value. As a result, five implicates were generated for each dataset. This study combined the five implicates into one dataset for statistical analysis using the "repeated-imputation inference" (RII) method (Kennickell \& Woodburn, 1999).

To apply survey weighting (X42001) and the 999 bootstrap replicate weights provided by SCF for correct error estimation, a complex survey command of STATA 12 software was used to run the model separately for each of five imputations (Kolenikov, 2010). The results of the five imputations were then combined in SAS 9.2 using the approach developed by Rubin (1976) and Rubin (1987). 
In the SCF, the "head" of a household with a central couple was designated to be either the male in a mixed-sex-couple household or the older individual in a same-sex-couple household, regardless of who was the respondent. When the respondent was not the head, all data for those two individuals were swapped. To match the respondent and his/her responses, the two individuals involved were switched back in this study.

The Age-Period-Cohort (APC) analysis has been widely employed in marketing research. In the APC analysis, period is the present year and cohort is the birth year. The APC analysis helps collectively analyze the effect of three time-related factors (age, period and cohort), which have an exact linear dependency relationship (period - cohort $=$ age). Contributions to the ageperiod-cohort effect on DC plan deferral rate may be: 1) a decreased work life expectancy when workers can save (age effect); 2) socioeconomic environments that influence everyone over time (period effect); and 3) socioeconomic environments that influence different generations (cohort effect). To address the well-known multicollinearity issue in APC models between age, cohort and survey period (Yang \& Land, 2008), respondent's age was coded at 10-year increments and cohort was coded into four generation cohorts. Variance Inflation Factor (VIF) statistics over 10 are often considered as indicating multicollinearity issues (Freund \& Wilson, 1998). This specification allows the VIF statistics to be within acceptable boundary of lower than 10 .

The dependent variable (rate of DC plan deferral) was expressed in the form of proportions with a range of $[0,1]$. The distribution of the deferral rate was asymmetric and violated the normality assumption for ordinary linear regression model. A Tobit regression would address the truncated nature of the data but still requires the symmetrical distribution assumption to hold. Ordered logistic regression and beta distribution are often used to deal with an asymmetric distribution that is between 0 and 1 . The adoption of beta distribution as a 
method requires a check of its model fit statistics. However, the bootstrap replicate weights estimation does not provide any model fit statistics such as Akaike Information Criterion (AIC). Categorizing the deferral rate into the several groups with a constant increment is a typical method of handling data with significant sequential order for the purpose of conducting an ordered logistic regression of deferral rate on the independent variables. The important assumption of an ordered logistic regression is that odds are proportional (Agresti, 2002). Since the dependent variable was originally a continuous variable and the new dependent variable was coded into six groups that had a natural order, it was reasonable to assume that one set of coefficients could explain the relationship between any two groups of outcome. Consequently, the ordered logistic regression was employed for the multivariate analysis.

\section{Results}

\section{Observed DC Deferral Rates over Time and by Sample Characteristics}

Table 1 shows the distribution of respondent's deferral to their DC plans as a percent of their maximum deferral amount. Overall, $61.3 \%$ of the total sample deferred less than $20 \%$ of their allowed amount. The patterns of the DC deferral rate across the six rate categories in 2004 and 2007 were very similar, with roughly half of the respondents deferring less than $20 \%$, a quarter of the respondents deferring $20-40 \%$ into their DC plans, and a little more than $7 \%$

maximizing their DC plan deferral. However, these percentages dropped dramatically in 2010, with $90.7 \%$ (compared to $43.1 \%$ in 2004 and $51.0 \%$ in 2007 ) deferring less than $20 \%, 1.9 \%$ (compared to $25.7 \%$ in 2004 and $23.1 \%$ in 2007 ) deferring $20-40 \%$, and $2.9 \%$ (compared to $7.2 \%$ in 2004 and $7.5 \%$ in 2007 ) deferring the maximum allowed amount. 
Older respondents deferred a higher percentage of their maximum allowed amount into their DC plans. More than 7\% of respondents older than 40 maximized their DC plan deferral, while only $4.7 \%$ for those $31-40$ years old and $0.9 \%$ for those younger than 30 maximized their deferral. The overwhelming majority (88.9\%) of the Y generation made deferrals of less than $20 \%$, and no one of this generation deferred more than $80 \%$ of their maximum allowed amount.

About half (49.6\%) of married males deferred less than $20 \%$, and $10.8 \%$ of them maximized their deferral. However, only $5.3 \%$ of single males, $2.0 \%$ of married females, and $1.9 \%$ of single females deferred their maximum amount. The percentage of respondents who deferred less than $20 \%$ decreased with education levels. Only $39.1 \%$ of respondents with a graduate or a professional degree deferred less than $20 \%$, and $14.6 \%$ of them deferred $100 \%$ of the allowed amount. However, for lower-educated respondents, the majority deferred less than $20 \%$, and the percentage deferring their maximum amount was less than $2.5 \%$ for those with a college degree or less. A higher percentage of whites and respondents of other races/ethnicities deferred $100 \%$ (6.7\% and $8.6 \%$, respectively). Only $2.0 \%$ black respondents deferred $100 \%$, and for Hispanics, this percentage was $1.4 \%$.

The overwhelming majority (65.0\%) of respondents who did not have a DB plan deferred less than $20 \%$ of their maximum amount into their DC plans, higher than the $47.2 \%$ of those who had at least one DB plan. More than twice (10.2\%) the respondents who had more than one DC plan maximized their deferral amount, compared to those who had only one DC plan (4.0\%). Respondents whose DC plan allowed them to borrow against the plan deferred a higher percentage of their maximum amount (6.7\% deferred $100 \%$ and $9.1 \%$ deferred $60-100 \%)$, compared to those who could not borrow against their plan (3.9\% deferred $100 \%$ and $5.3 \%$ deferred $60-100 \%)$. The patterns of deferral rate were similar for respondents who were allowed 
to withdraw from their DC plans and those who could not. Respondents whose employer matched their deferral deferred a lower percentage of their maximum amount $(5.5 \%$ deferred $100 \%$ and $7.8 \%$ deferred $60-100 \%$ ), compared to those where employers did not provide a match (7.9\% deferred $100 \%$ and $9.1 \%$ deferred $60-100 \%)$.

Among the home ownership groups, $75.9 \%$ of renters deferred less than $20 \%$, and $2.2 \%$ of them deferred $100 \%$. The percentages for homeowners with a home loan were $56.4 \%$ and $9.9 \%$, respectively. Respondents with higher deferral rates also had a higher income and net worth. For example, the average income was $\$ 77,691$ for those who deferred $0-20 \%$ and $\$ 371,100$ for those who had a $100 \%$ deferral rate. Respondents with incomes higher than normal had a higher deferral rate than those with incomes lower than normal or about the same. More than one-tenth (13.1\%) of the respondents whose income were higher than normal maximized their deferral amount. However, for those who had a lower-than-normal income, only $6.3 \%$ deferred $100 \%$.

Most (82.3\%) respondents who were not willing to take any risks deferred $0-20 \%$ of their maximum allowed amount into their DC plans, and only $6.5 \%$ of them deferred more than $40 \%$. However, $10.2 \%$ of respondents with an above-average risk tolerance level maximized their DC deferral, and more than one-third (34.1\%) of them deferred more than $40 \%$. Respondents who expected a large asset transfer in the future deferred less than those who did not have such an expectation. The patterns of the DC deferral rate across the six rate categories were very similar among the groups who had different expectations of the U.S. economy's performance in the future. Respondents who overspent deferred less than those who did not overspend. For example, $72.5 \%$ of overspenders deferred $0-20 \%$, and only $2.7 \%$ of them maximized their deferral. However, these rates for those who did not overspend were $59.2 \%$ and $6.5 \%$, 
respectively. Around one-tenth of respondents who expected a very satisfactory $(10.6 \%)$ or a satisfactory (9.0\%) retirement income from Social Security and job pensions maximized their DC deferral. However, only $3.4 \%$ of those who expected such income to be inadequate deferred $100 \%$. Respondents with a better perceived health status had higher deferral rates than those who perceived a worse health status. The percent who deferred $100 \%$ ranged from $1.1 \%$ for the poor health group to $8.1 \%$ to the excellent health group.

\section{Ordered Logistic Results}

The results of ordered logistic regression (Table 2) showed that respondents who: were middle-aged (41-50 years old), were single makes, had more education, were in excellent health, with more income, willing to take investment risk, were allowed to borrow from the DC plan, were allowed to withdraw from the DC plan, were homeowners with a mortgage, and had retirement as a saving motive were more likely to make a larger deferral to the DC plan.

Compared with respondents in the 41-50 age group, the odds of both the young group (21-30) and an older group (51-60) to have a higher deferral rate were lower $(65.6 \%$ and $81.3 \%$, respectively). This non-linear relationship between age and DC deferral rate was inconsistent with findings from prior research that showed a positive relationship between these two variables. After controlling for other factors, the interaction term between employer's match and period 2004 was statistically significant; the effect of employer's match and period on deferral rate should be analyzed together. Results from a separate analysis (not shown in tables) showed the percent of respondents whose employer match their DC deferral was $15.6 \%$ in $2004,16.4 \%$ in 2007 , and $20.2 \%$ in 2010 . A chi-square test of these percentages did not show any significant statistical difference. The odds of deferring a higher rate were not significantly different between 2004 and 2007. However, the odds of having a higher deferral rate for respondents in 
2007 were 27.8 times as high as the odds for respondents in 2010 . In 2004, the odds of having a higher deferral rate for respondents with employer's match were 3.8\% lower than those whose employer did not provide a match. In both 2007 and 2010, the odds of having a higher deferral rate for respondents with a match were $48.2 \%$ as high as the odds for those who did not have a match from their employer.

Controlling for other factors, married females had the lowest odds to defer a higher rate among all respondents, consistent with research findings from Bajtelsmit et al. (1999) and Huberman et al. (2007). Compared with married females, the odds of deferring a higher rate were 1.6 times higher for single females, 1.7 times higher for married males, and 3.0 times higher for single males. Consistent with findings from previous research ((Bassett, Fleming, \& Rodrigues, 1998; DeVaney \& Zhang; 2001; Joo \& Grable, 2005), education had a positive effect on DC deferral rate. For example, the odds of deferring a higher rate for those with a graduate or a professional degree were $156.3 \%$ higher than the odds for high school diploma holders. The odds of deferring a higher rate for respondents in the "other" race group were $53.2 \%$ higher than the odds for white respondents. This result confirms findings by Yuh and DeVaney (1996).

The odds of having a higher deferral rate for respondents who had only one DC plan were $39.9 \%$ as high as those who had multiple DC plans. Consistent with findings from Holden and VanDerhei (2001) and Xiao (1997), the potential accessibility to DC plan assets (e.g. the ability to borrow and withdraw) increased the odds of deferring a higher rate. Compared with homeowners with a home loan, the odds for homeowners without a loan were $60.4 \%$ as high and the odds for renters were $63.1 \%$ as high. Total household income had a significant positive relationship with the odds of deferring a higher rate, which was consistent with findings from prior research (DeVaney \& Zhang, 2001; Dushi et al. 2011; Huberman et al. 2007; Papke, 2003). 
Respondents whose income was lower than normal had the highest odds of deferring a higher rate than those whose income was equal to or higher than normal. Consistent with prior research findings (Xiao, 1997; Yuh \& DeVaney, 1996), risk tolerance positively affected the DC plan deferral rage. Compared with respondents willing to take average risks, the odds of deferring a higher rate for those unwilling to take any risk were $72.4 \%$ as high, and the odds for those with an above-average risk tolerance were 1.4 times as high. Lower expectations of the future U.S. economic performance and having retirement as a saving motive increased the odds of deferring a higher rate. The odds of deferring a higher rate for respondents with an excellent selfperceived health status were 1.2 times as high as the odds for those who reported good health status.

\section{Discussion and Implications}

The Life Cycle Hypothesis (Ando \& Modigliani, 1963) suggests that individuals accumulate wealth during work years to finance consumption after retirement. Based on this hypothesis and a few assumptions and expectations (e.g. retirement age, life expectancy, expected portfolio return), individuals should develop a saving strategy to be on track for saving for retirement. DC plan deferral should increase during years when portfolio returns are low. In years when portfolio returns are high, the deferral does not need to increase. Given the total amount of savings needed, participants whose employer does not match their deferral should contribute a higher amount than those who receives a match from their employer. However, findings of this study showed that individuals do not follow this strategy. Facing both the changes in two of the three major sources of retirement income and the longevity risk, individuals eligible for DC plans should be careful to avoid retirement saving mistakes. 
Researchers, financial professionals, employers and policy makers should utilize results of this study to better facilitate the general public's retirement preparation.

According to Bucks et al. (2009), most SCF interviews were conducted between May and December of the survey year. As shown in Figure 1, the average monthly S\&P 500 real rates of return during the interview period decreased from the $1.3 \%$ in 2004 to $0.1 \%$ in 2007 and went back up to $1.1 \%$ in 2010 . The percentages of respondents interviewed in each month were unknown. Assuming the distributions of respondents being interviewed in those months in all survey years were even, the average monthly return is a good measure of $r_{t}$. It is reasonable to assume the market returns and the individual portfolio returns have a positive relationship. Based on $\mathrm{H}_{1}$, participants would defer a higher amount in 2007 than in 2004 and 2010 and would not defer a higher amount in 2004 than in 2007 and 2010. This hypothesis was partially rejected by the order logistic results in that the difference between the deferral rates in 2004 and 2007 was not statistically significant; participants deferred a significantly lower amount, as a percentage of their maximum allowed amount, in 2010 than in prior years. Based on $\mathrm{H}_{2}$, respondents who received a match should be expected to defer a lower amount as a percent of their maximum allowed amount into their DC plan. This hypothesis was confirmed by the ordered logistic results.

Year 2010 was a very different year from the two prior survey years. In the Great Recession, some employers reduced or suspended their DC plan contribution to employees. This may be the reason why the percentage of eligible participants in 2010 was lower than in 2004 and 2007. Since this study was focused on the DC plan deferral behavior, this study's research scope was limited to eligible employees; those who became ineligible in 2010 due to the change in employer's match were excluded. Although their retirement adequacy may be in jeopardy, 
this is not something the employees could change other than saving more in other retirement accounts or non-tax-advantaged accounts.

The last survey year was also different from prior survey years in that it followed the Great Recession. Although the proportion of respondents (eligible participants) who received an employer's match was not statistically lower in 2010 than in prior years, it is very plausible that some employers reduced their match in the recession and had not restored it by 2010 . Moreover, the mean monthly market return was lower in 2010 than in 2004. Both these factors should have induced a higher deferral rate in 2010 than in 2004. However, results from the ordered logistic analysis were contrary to the anticipated result. By examining Figure 1, one can tell that the standard deviations of the monthly market returns during the 2004 and 2007 survey months were very similar (2.2\% and $2.9 \%$, respectively), which were much lower than the standard deviation for the same months in $2010(6.4 \%)$. It is probable that instead of acting on the size of the real rates of market return, respondents make DC plan deferral decisions based on the volatility of the returns. It is also possible that some respondents were still reacting to the market volatility in the recession. If the decrease in deferral rate in 2010 was due to a fear factor of the market volatility, DC plan participants have missed the opportunity of buying low and, more importantly, may have also fallen behind on their retirement wealth accumulation. Researchers, financial professionals, employers and policy makers should help DC plan participants overcome such behavior and make a DC plan deferral decision that is more in line with their retirement saving goal.

Having experienced the past economic recession and facing Social Security’s uncertain future and the risk of securing a satisfactory standard of living in retirement, strategic and disciplined deferrals to DC plans have become more important than ever for eligible participants. 
Deviations from this saving behavior would increase the likelihood of an inadequate retirement wealth and, consequently, the likelihood of retirees outliving their retirement resources. Results of this study provide a description and a possible explanation of participants' DC deferral behavior in different economic environments. Future research is needed to explore reasons for such behavior and provide methods and policies to compensate for this less-than-optimal behavior. It is also important that researchers, employers, financial educators and financial practitioners help the current workforce better understand the challenges they face and become on-track for their retirement savings.

\section{Limitations and Future Research}

This study has a few limitations. The first two are due to the availability of data. It would be best to examine deferral behavior before, during, and after the Great Recession to produce results that describe the effect of the recession on DC plan deferral behavior. According to the National Bureau of Economic Research's Business Cycle Dating Committee, the recession started in December 2007 and ended in June 2009. In the available sample of this study, all of 2004 and most of 2007 SCF respondents were interviewed before the recession, and all 2010 respondents were interviewed almost a year after the recession. Although the SCF reinterviewed the 2007 participants in 2009, respondents were not asked to provide DC deferral information in that study. The Pension Protection Act of 2006 and the size of employers' match should have an effect on participants' DC plan deferral rate. However, their effect on the deferral amount should be different for various types of participants, depending on their use of the employer's match. Due to the data limitation, the degree of employer's match could not be determined. Therefore, the employer's match (yes vs. no) entered the multivariate analysis as a control variable. 
Past research has shown that spousal employment status, pension plan ownership and DC plan deferral rate also affect respondents' DC plan deferral behavior. However, the presence of spouses, their pension plan ownership and deferral behavior, and the period dummies created a significant collinearity problem not resolved by including interaction terms between those variables. Therefore, the presence of spouses and their pension plan ownership and deferral rate were excluded from the model. The last limitation is the nature of the data. The most suitable data for this type of analysis is longitudinal data, but currently available, nationally representative longitudinal data do not include information on DC plan deferral.

The results of this study describe a national trend of DC plan deferral and can provide useful information to researchers, financial professionals, employers and policy makers with regard to DC plan participants' behavior in different economic environments. The results can be utilized by them to better facilitate retirement preparation of the general public. Future research may benefit from a longitudinal survey designed for analysis of individual retirement savings, specifically, their DC plan deferral. 


\section{References}

Agresti, A. (2002). Categorical Data Analysis. Hoboken, NJ: John Wiley and Sons.

Ando, A., \& Modigliani, F. (1963). The life cycle hypothesis of saving: Aggregate implications and tests. American Economic Review, 53(1), 55-84.

Bajtelsmit, V. L., Bernasek, A., \& Jianakoplos, N. A. (1999). Gender differences in defined contribution pension decisions. Financial Services Review, 8(1), 1-10.

Bassett, W. F., Fleming, M. J., \& Rodrigues, A. P. (June 1998). How workers use 401(k) plans: The participation, contribution, and withdrawal decisions. National Tax Journal, 51(2), 263289.

Bricker, J., Kennickell, A. B., Moore, K. B., \& Sabelhaus, J. (February 2012). Changes in U.S. family finances from 2007 to 2010: Evidence from the Survey of Consumer Finances. Federal Reserve Bulletin, 98(2), retrieved November 6, 2012, from http://www.federalreserve.gov/pubs/bulletin/2012/PDF/scf12.pdf

Bucks, B. K., Kennickell, A. B., Mach, T. L., \& Moore, K. B. (2009). Changes in U.S. family finances from 2004 to 2007: Evidence from the Survey of Consumer Finances. Federal Reserve Bulletin, 95, A1-A55.

Butrica, B. A., \& Smith, K. E. (August 2012). 401(k) Participant Behavior in a Volatile Economy. Paper presented at the $14^{\text {th }}$ Annual Joint Conference of the Retirement Research Consortium, Washington. Abstract retrieved October 30, 2012, from http://www.nber.org/programs/ag/rrc/rrc2012/summaries/2.3\%20Butrica,\%20Smith.pdf

Ciccone, S. (2011). Investor optimism, false hopes and the January effect. Journal of Behavioral Finance, 12(3), 158-168. 
Cunningham, C. R., \& Engelhardt, G. V. (2002). Federal tax policy, employer matching, and 401(k) saving: Evidence from HRS W-2 records. National Tax Journal, 55(3), 617-645.

DeVaney, S. A., Zhang, T. C. (2001). A cohort analysis of the amount in defined contribution and individual retirement accounts. Financial Counseling and Planning, 12(1), 89-104.

Dushi, I., \& Iams, H. M. (2008). Cohort differences in wealth and pension participation of nearretirees. Social Security Bulletin, 68(3): 45-66.

Dushi, I., Iams, H. M., \& Tamborini, C. R. (2011). Defined contribution pension participation and contributions by earnings levels using administrative data. Social Security Bulletin, 71(2), 67-76.

Engelhardt, G., \& Kumar, A. (2007). Employer matching and 401(k) saving: Evidence from the health and retirement study. Journal of Public Economics, 91(10), 1920-1943.

Freund, R. J., \& Wilson, W. J. (1998). Regression analysis. San Diego: Academic Press.

Hassan, M. K., \& Lawrence, S. (2001). The decision to defer: Factors affecting employee deferral incentives. Financial Services Review, 10, 45-54.

Hastings, J. S., \& Mitchell, O. S. (2011). How Financial Literacy and Impatience Shape Retirement Wealth and Investment Behaviors. NBER Working Paper No. 16740. Retrieved August 22, 2012, from http://www.nber.org/papers/w16740

Holden, S., \& VanDerhei, J. (2001). Contribution behavior of 401(k) plan participants. Investment Company Institute Perspective, 7(4), 1-20.

Honig, M., \& Dushi, I. (2009). Participation and Contribution in Tax-deferred Retirement Accounts: Evidence from Social Security Records. Michigan Retirement Research Center Working Paper No. 2009-216. Retrieved November 20, 2012, from 
http://141.213.232.243/bitstream/handle/2027.42/65065/wp219.pdf;jsessionid=A4341BC3A F603A984D8D003571EBFC72?sequence=1

Huberman, G., Iyengar, S. S., \& Jiang, W. (2007). Defined contribution pension plans:

Determinants of participation and contribution rates. Journal of Financial Services Research, $31(1), 1-32$.

Internal Revenue Service. (2013). Tax-Sheltered Annuity Plans (403(b) Plans) (IRS Publication No. 571). Washington, DC: U.S. Government Printing Office.

Joo, S., \& Grable, J. E. (2005). Employee education and the likelihood of having a retirement savings program. Financial Counseling and Planning, 16(1), 37-49.

Kennickell, A. B., \& Woodburn, L. R. (1999). Consistent weight design for the 1989, 1992, and 1995 SCFs and the distribution of wealth. Review of Income and Wealth, 45, 193-215.

Kusko, A. L., Poterba, J. M., \& Wilcox, D. W. (1994). Employee decisions with respect to 401(k) plans: Evidence from individual-level data. NBER Working Paper No. 4635. Retrieved August 22, 2012, from http://www.nber.org//papers/w4635

Kolenikov, S. (2010). Resampling variance estimation for complex survey data. The Stata Journal, 10(2), 165-199.

Montalto, C. P. (March 1998). Everything You Always Wanted to Know About the Survey of Consumer Finances. Paper presented at the 1998 Annual Meeting of the American Council on Consumer Interests. Article retrieved November 6, 2012, from http://legacy.ehe.osu.edu/cs/scf/cmacci98.htm

Munnell, A., \& Sundén, A. (2004). Coming Up Short: The Challenge of 401(k) Plans. Washington: Brookings Institution Press. 
Papke, L. E. (1992). Participation In and Contribution to 401(k)Pension Plans: Evidence from Plan Data. NBER Working Paper No. 4199. Retrieved August 22, 2012, from http://www.nber.org//papers/w4199

Papke, L. E. (2003). Individual financial decisions in retirement plans: The role of participantdirection. Journal of Public Economics, 88, 39-61.

Pattison, D., \& Waldron, H. (2008). Trends in Elective Deferrals of Earnings from 1990-2001 in Social Security Administrative Data. Social Security Administration ORDP Research and Statistics Note No. 2008-03. Retrieved August 22, 2012, from www.socialsecurity.gov/policy

Pension Protection Act of 2006, Pub. L. No. 109-280, 104 Stat. 780 (2006).

Rubin, D. B. (1976). Inference and missing data. Biometrika, 63(3), 581-592.

Rubin, D. B. (1987). Multiple Imputation for Nonresponse in Surveys. New York: John Wiley \& Sons.

Schleef, H. J., \& Eisinger, R. M. (2007). Hitting or missing the retirement target: Comparing contribution and asset allocation schemes of simulated portfolios. Financial Services Review, 16, 229-243.

Sharpe, W. (1964). Capital asset prices: A theory of market equilibrium under conditions of risk. Journal of Finance, 19, 425-442.

Social Security Board of Trustees (2011). Projected Trust Fund Exhaustion One Year Sooner. Retrieved June 02, 2011, from http://www.ssa.gov/pressoffice/pr/trustee11-pr.htm Statman, M., Thorley, S., \& Vorkink, K. (2006). Investor overconfidence and trading volume. Review of Financial Studies, 19, 1531-1565. 
U.S. Department of Labor Employee Benefits Security Administration. (November 2012). Private Pension Plan Bulletin Historical Tables and Graphs. Retrieved May 15, 2013, from: http://www.dol.gov/ebsa/pdf/historicaltables.pdf

U.S. National Center for Health Statistics. (2012). Table 104. Expectation of life at birth, 1970 to 2008, and projections, 2010 to 2020. Statistical abstract of the United States: 2012.

Washington, D.C.: U.S. Census Bureau.

Utkus, S. P., \& Young, J. A. (March 2011). The great recession and 401(k) plan participant behavior. Vanguard Research. Retrieved October 21, 2012, from https://institutional.vanguard.com/iam/pdf/CRRGR.pdf

Wiatrowski, W. J. (2004). Medical and retirement plan coverage: Exploring the decline in recent years. Monthly Labor Review, 127(8), 29-36.

Xiao, J. J. (1997). Saving motives and 401(k) contributions. Financial Counseling and Planning, $8(2), 65-73$.

Yang, Y., \& Land, K.C. (2006). A mixed models approach to the age-period-cohort analysis of repeated cross-section surveys: Trends in verbal test scores. Sociological Methodology, 36, $75-97$.

Yang, Y., \& Land, K.C. (2008). Age-period-cohort analysis of repeated cross-section surveys: Fixed or random effects? Sociological Methods and Research, 36(3), 297-326.

Yao, R. (2011). Market returns affect risk tolerance. Corporate Finance Review, 15(5), 5-9.

Yao, R., Sharpe, D. L., \& Wang, F. (2011). Decomposing the age effect on risk tolerance. Journal of Socio-Economics, 40(6), 879-887. 
Yuh, Y. (2011). Assessing adequacy of retirement income for U.S. households: A replacement ratio approach. The Geneva Papers on Risk and Insurance - Issues and Practice, 36, 304323.

Yuh, Y., \& DeVaney, S. A. (1996). Determinants of couples' defined contribution retirement funds. Financial Counseling and Planning, 7, 31-38.

Zhou, J. (2009). The effects of employer matching and income risk in 401(k) plans. Economic Modeling, 26(6), 1193-1200. 
Table 1. DC Plan Deferral Rates by Sample Characteristics

\begin{tabular}{|c|c|c|c|c|c|c|}
\hline \multirow{2}{*}{ Sample Characteristics } & \multicolumn{6}{|c|}{ DC Plan Deferral Rates } \\
\hline & $0-20 \%$ & $20 \%-40 \%$ & $40 \%-60 \%$ & $60 \%-80 \%$ & $80 \%-100 \%$ & $100 \%$ \\
\hline Overall & $61.3 \%$ & $17.1 \%$ & $7.8 \%$ & $4.3 \%$ & $3.7 \%$ & $5.9 \%$ \\
\hline \multicolumn{7}{|l|}{ Age-Period-Cohort } \\
\hline \multicolumn{7}{|l|}{ Age } \\
\hline $21-30$ & $73.1 \%$ & $17.4 \%$ & $4.7 \%$ & $2.2 \%$ & $1.7 \%$ & $0.9 \%$ \\
\hline $31-40$ & $63.4 \%$ & $17.4 \%$ & $8.4 \%$ & $3.2 \%$ & $2.9 \%$ & $4.7 \%$ \\
\hline $41-50$ & $57.8 \%$ & $17.7 \%$ & $8.8 \%$ & $5.0 \%$ & $3.5 \%$ & $7.3 \%$ \\
\hline $51-60$ & $58.9 \%$ & $16.3 \%$ & $7.8 \%$ & $4.6 \%$ & $4.8 \%$ & $7.6 \%$ \\
\hline $61-70$ & $54.5 \%$ & $16.1 \%$ & $6.5 \%$ & $8.2 \%$ & $7.2 \%$ & $7.6 \%$ \\
\hline \multicolumn{7}{|l|}{ Period } \\
\hline 2004 & $43.1 \%$ & $25.7 \%$ & $13.2 \%$ & $5.9 \%$ & $4.8 \%$ & $7.2 \%$ \\
\hline 2007 & $51.0 \%$ & $23.1 \%$ & $9.0 \%$ & $5.5 \%$ & $3.8 \%$ & $7.5 \%$ \\
\hline 2010 & $90.7 \%$ & $1.9 \%$ & $0.9 \%$ & $1.4 \%$ & $2.4 \%$ & $2.9 \%$ \\
\hline \multicolumn{7}{|l|}{ Cohort } \\
\hline Silent generation & $44.4 \%$ & $21.5 \%$ & $9.3 \%$ & $8.3 \%$ & $8.5 \%$ & $8.0 \%$ \\
\hline Baby boom generation & $56.3 \%$ & $17.9 \%$ & $8.7 \%$ & $5.2 \%$ & $4.3 \%$ & $7.6 \%$ \\
\hline $\mathrm{X}$ generation & $66.4 \%$ & $16.5 \%$ & $7.3 \%$ & $2.9 \%$ & $2.8 \%$ & $4.1 \%$ \\
\hline Y generation & $88.9 \%$ & $9.5 \%$ & $0.2 \%$ & $1.4 \%$ & $0.0 \%$ & $0.0 \%$ \\
\hline \multicolumn{7}{|l|}{ Demographic Characteristics } \\
\hline \multicolumn{7}{|l|}{ Household type } \\
\hline Married male & $49.6 \%$ & $17.9 \%$ & $8.9 \%$ & $6.2 \%$ & $6.6 \%$ & $10.8 \%$ \\
\hline Married female & $70.4 \%$ & $15.5 \%$ & $7.2 \%$ & $3.6 \%$ & $1.2 \%$ & $2.0 \%$ \\
\hline Single male & $59.8 \%$ & $17.5 \%$ & $9.2 \%$ & $4.4 \%$ & $3.8 \%$ & $5.3 \%$ \\
\hline Single female & $73.0 \%$ & $17.4 \%$ & $5.3 \%$ & $1.4 \%$ & $1.1 \%$ & $1.9 \%$ \\
\hline Number of children (average) & 1.0 & 0.9 & 0.9 & 1.0 & 0.9 & 1.2 \\
\hline \multicolumn{7}{|l|}{ Education } \\
\hline Less than high school & $85.7 \%$ & $6.0 \%$ & $3.6 \%$ & $2.0 \%$ & $2.8 \%$ & $0.0 \%$ \\
\hline High school diploma & $79.8 \%$ & $12.3 \%$ & $4.1 \%$ & $1.8 \%$ & $0.7 \%$ & $1.3 \%$ \\
\hline Some college & $68.3 \%$ & $18.7 \%$ & $6.6 \%$ & $2.8 \%$ & $1.1 \%$ & $2.4 \%$ \\
\hline Bachelor's degree & $54.2 \%$ & $18.0 \%$ & $10.0 \%$ & $5.4 \%$ & $5.4 \%$ & $7.0 \%$ \\
\hline $\begin{array}{l}\text { Graduate or professional } \\
\text { degree }\end{array}$ & $39.1 \%$ & $20.1 \%$ & $10.4 \%$ & $7.7 \%$ & $8.1 \%$ & $14.6 \%$ \\
\hline \multicolumn{7}{|l|}{ Race/Ethnicity } \\
\hline White & $59.4 \%$ & $17.4 \%$ & $7.7 \%$ & $4.7 \%$ & $4.0 \%$ & $6.7 \%$ \\
\hline Black & $69.8 \%$ & $16.8 \%$ & $7.2 \%$ & $3.2 \%$ & $1.0 \%$ & $2.0 \%$ \\
\hline Hispanic & $75.2 \%$ & $14.9 \%$ & $5.9 \%$ & $1.6 \%$ & $1.1 \%$ & $1.4 \%$ \\
\hline Other & $52.9 \%$ & $16.4 \%$ & $11.1 \%$ & $3.7 \%$ & $7.2 \%$ & $8.6 \%$ \\
\hline \multicolumn{7}{|c|}{ Feature of Respondent's Pension Plans } \\
\hline \multicolumn{7}{|l|}{ Have DB plan(s) } \\
\hline Yes & $47.2 \%$ & $23.0 \%$ & $10.0 \%$ & $5.9 \%$ & $5.8 \%$ & $8.1 \%$ \\
\hline No & $65.0 \%$ & $15.5 \%$ & $7.2 \%$ & $3.9 \%$ & $3.1 \%$ & $5.3 \%$ \\
\hline \multicolumn{7}{|l|}{ Only one DC plan } \\
\hline Yes & $68.5 \%$ & $15.3 \%$ & $6.0 \%$ & $3.6 \%$ & $2.5 \%$ & $4.0 \%$ \\
\hline No & $44.7 \%$ & $21.2 \%$ & $11.7 \%$ & $5.8 \%$ & $6.4 \%$ & $10.2 \%$ \\
\hline
\end{tabular}




\begin{tabular}{|c|c|c|c|c|c|c|}
\hline Yes & $57.0 \%$ & $18.7 \%$ & $8.5 \%$ & $4.6 \%$ & $4.5 \%$ & $6.7 \%$ \\
\hline No & $71.6 \%$ & $13.3 \%$ & $5.9 \%$ & $3.5 \%$ & $1.8 \%$ & $3.9 \%$ \\
\hline \multicolumn{7}{|l|}{ Allow to withdraw } \\
\hline Yes & $61.0 \%$ & $16.6 \%$ & $8.1 \%$ & $4.3 \%$ & $3.9 \%$ & $6.1 \%$ \\
\hline No & $61.8 \%$ & $18.5 \%$ & $6.9 \%$ & $4.2 \%$ & $3.2 \%$ & $5.3 \%$ \\
\hline \multicolumn{7}{|l|}{ Employer's match } \\
\hline Yes & $62.2 \%$ & $16.8 \%$ & $7.7 \%$ & $4.2 \%$ & $3.6 \%$ & $5.5 \%$ \\
\hline No & $57.0 \%$ & $18.3 \%$ & $7.8 \%$ & $5.0 \%$ & $4.1 \%$ & $7.9 \%$ \\
\hline \multicolumn{7}{|l|}{ Economic Situations } \\
\hline \multicolumn{7}{|l|}{ Home ownership } \\
\hline Rent & $75.9 \%$ & $14.7 \%$ & $3.1 \%$ & $2.5 \%$ & $1.5 \%$ & $2.2 \%$ \\
\hline Own w/ loan & $56.4 \%$ & $14.5 \%$ & $8.5 \%$ & $5.5 \%$ & $5.2 \%$ & $9.9 \%$ \\
\hline Own w/o loan & $58.0 \%$ & $18.1 \%$ & $8.9 \%$ & $4.6 \%$ & $4.1 \%$ & $6.3 \%$ \\
\hline Job Tenure (average) & 9.8 & 10.9 & 12.2 & 12.9 & 11.7 & 14.3 \\
\hline \multicolumn{7}{|l|}{ Total household income } \\
\hline$\leq \$ 25,000$ & $92.6 \%$ & $6.1 \%$ & $1.0 \%$ & $0.0 \%$ & $0.0 \%$ & $0.4 \%$ \\
\hline$\$ 25,001-\$ 50,000$ & $82.5 \%$ & $13.8 \%$ & $2.7 \%$ & $0.6 \%$ & $0.4 \%$ & $0.0 \%$ \\
\hline$\$ 50,001-\$ 75,000$ & $69.6 \%$ & $20.0 \%$ & $7.0 \%$ & $1.4 \%$ & $1.4 \%$ & $0.7 \%$ \\
\hline$\$ 75,001-\$ 100,000$ & $58.5 \%$ & $20.6 \%$ & $11.2 \%$ & $4.7 \%$ & $3.3 \%$ & $1.7 \%$ \\
\hline$>100000$ & $37.2 \%$ & $17.5 \%$ & $11.2 \%$ & $9.4 \%$ & $8.3 \%$ & $16.5 \%$ \\
\hline Mean & $\$ 77,691$ & $\$ 102,868$ & $\$ 127,764$ & $\$ 218,956$ & $\$ 269,191$ & $\$ 371,100$ \\
\hline Median & $\$ 60,867$ & $\$ 77,998$ & $\$ 98,282$ & $\$ 126,794$ & $\$ 151,518$ & $\$ 209,465$ \\
\hline \multicolumn{7}{|c|}{ Current income vs. normal income } \\
\hline Higher & $50.2 \%$ & $17.4 \%$ & $9.1 \%$ & $5.9 \%$ & $4.4 \%$ & $13.1 \%$ \\
\hline About the same & $61.3 \%$ & $17.5 \%$ & $8.0 \%$ & $4.5 \%$ & $3.8 \%$ & $4.9 \%$ \\
\hline Lower & $70.0 \%$ & $14.7 \%$ & $5.2 \%$ & $1.6 \%$ & $2.3 \%$ & $6.3 \%$ \\
\hline \multicolumn{7}{|l|}{ Household net worth } \\
\hline$\leq 0$ & $91.2 \%$ & $6.3 \%$ & $1.8 \%$ & $0.0 \%$ & $0.0 \%$ & $0.6 \%$ \\
\hline $1-\$ 200,000$ & $76.1 \%$ & $16.1 \%$ & $4.3 \%$ & $1.9 \%$ & $1.0 \%$ & $0.7 \%$ \\
\hline$\$ 200,001-\$ 600,000$ & $50.9 \%$ & $22.7 \%$ & $12.4 \%$ & $6.1 \%$ & $3.5 \%$ & $4.4 \%$ \\
\hline$\$ 600,001-\$ 1,200,000$ & $32.3 \%$ & $19.6 \%$ & $12.6 \%$ & $10.6 \%$ & $11.4 \%$ & $13.5 \%$ \\
\hline$>1200000$ & $27.8 \%$ & $8.4 \%$ & $7.4 \%$ & $10.7 \%$ & $12.3 \%$ & $33.4 \%$ \\
\hline Mean & $\$ 287,452$ & $\$ 469,385$ & $\$ 715,376$ & $\$ 1,458,006$ & $\$ 2,096,689$ & $\$ 2,978,091$ \\
\hline Median & $\$ 93,574$ & $\$ 207,043$ & $\$ 317,124$ & $\$ 527,021$ & $\$ 751,521$ & $\$ 1,242,115$ \\
\hline \multicolumn{7}{|l|}{ Respondent's Expectations } \\
\hline \multicolumn{7}{|l|}{ Risk tolerance } \\
\hline No risk & $82.3 \%$ & $11.3 \%$ & $2.6 \%$ & $1.3 \%$ & $1.1 \%$ & $1.5 \%$ \\
\hline Average & $60.1 \%$ & $18.8 \%$ & $7.7 \%$ & $4.2 \%$ & $3.7 \%$ & $5.5 \%$ \\
\hline Above average & $47.5 \%$ & $18.3 \%$ & $11.5 \%$ & $6.3 \%$ & $6.1 \%$ & $10.2 \%$ \\
\hline Substantial risk & $58.0 \%$ & $18.7 \%$ & $9.4 \%$ & $6.8 \%$ & $1.4 \%$ & $5.7 \%$ \\
\hline \multicolumn{7}{|c|}{ Expecting to receive large asset transfer in the future } \\
\hline Yes & $53.5 \%$ & $19.2 \%$ & $10.5 \%$ & $3.9 \%$ & $3.4 \%$ & $9.4 \%$ \\
\hline No & $63.1 \%$ & $16.6 \%$ & $7.1 \%$ & $4.4 \%$ & $3.7 \%$ & $5.1 \%$ \\
\hline \multicolumn{7}{|c|}{ Expectation of future U.S. economy } \\
\hline Better & $63.5 \%$ & $15.2 \%$ & $8.6 \%$ & $4.2 \%$ & $3.5 \%$ & $5.1 \%$ \\
\hline About the same & $59.0 \%$ & $17.9 \%$ & $7.5 \%$ & $4.3 \%$ & $4.1 \%$ & $7.3 \%$ \\
\hline Worse & $60.6 \%$ & $19.9 \%$ & $6.3 \%$ & $4.7 \%$ & $3.4 \%$ & $5.1 \%$ \\
\hline
\end{tabular}




\begin{tabular}{|c|c|c|c|c|c|c|}
\hline Yes & $72.5 \%$ & $13.7 \%$ & $7.1 \%$ & $3.0 \%$ & $1.0 \%$ & $2.7 \%$ \\
\hline No & $59.2 \%$ & $17.7 \%$ & $7.9 \%$ & $4.5 \%$ & $4.2 \%$ & $6.5 \%$ \\
\hline \multicolumn{7}{|l|}{ Retirement as a saving motive } \\
\hline Yes & $56.2 \%$ & $17.9 \%$ & $8.8 \%$ & $5.1 \%$ & $4.7 \%$ & $7.3 \%$ \\
\hline No & $71.7 \%$ & $15.5 \%$ & $5.6 \%$ & $2.5 \%$ & $1.7 \%$ & $3.0 \%$ \\
\hline \multicolumn{7}{|l|}{ Self-perceived retirement adequacy } \\
\hline Total inadequate & $66.1 \%$ & $14.9 \%$ & $5.5 \%$ & $4.3 \%$ & $3.1 \%$ & $6.0 \%$ \\
\hline Inadequate & $64.9 \%$ & $15.0 \%$ & $8.5 \%$ & $3.9 \%$ & $4.2 \%$ & $3.5 \%$ \\
\hline $\begin{array}{l}\text { Enough to maintain standard of } \\
\text { living }\end{array}$ & $61.8 \%$ & $18.2 \%$ & $8.0 \%$ & $4.0 \%$ & $3.0 \%$ & $5.0 \%$ \\
\hline Satisfactory & $50.8 \%$ & $19.2 \%$ & $10.0 \%$ & $5.9 \%$ & $4.9 \%$ & $9.0 \%$ \\
\hline Very satisfactory & $56.6 \%$ & $18.5 \%$ & $5.7 \%$ & $3.8 \%$ & $4.9 \%$ & $10.6 \%$ \\
\hline \multicolumn{7}{|l|}{ Self-perceived health condition } \\
\hline Excellent health & $54.6 \%$ & $17.1 \%$ & $9.6 \%$ & $5.3 \%$ & $5.3 \%$ & $8.1 \%$ \\
\hline Good health & $63.2 \%$ & $17.8 \%$ & $6.4 \%$ & $4.2 \%$ & $3.2 \%$ & $5.2 \%$ \\
\hline Fair health & $71.8 \%$ & $13.4 \%$ & $9.2 \%$ & $1.6 \%$ & $1.2 \%$ & $2.8 \%$ \\
\hline Poor health & $81.8 \%$ & $17.0 \%$ & $0.0 \%$ & $0.0 \%$ & $0.0 \%$ & $1.1 \%$ \\
\hline
\end{tabular}

Analysis of the 2004-2010 Survey of Consumer Finance; weighted results; sample size=3,502. 
Table 2. Ordered Logistic Analysis of Employees' DC Plan Deferral Rate

\begin{tabular}{|c|c|c|c|}
\hline Parameter & \multicolumn{2}{|c|}{ Coefficient } & Odds Ratio \\
\hline Intercept for $1^{\text {st }}$ group $(0-20 \%)$ & \multicolumn{2}{|l|}{0.1036} & \\
\hline Intercept for $2^{\text {nd }}$ group $(20-40 \%)$ & \multicolumn{2}{|l|}{1.6089} & \\
\hline Intercept for $3^{\text {rd }}$ group $(40-60 \%)$ & \multicolumn{2}{|l|}{2.4992} & \\
\hline Intercept for $4^{\text {th }}$ group $(60-80 \%)$ & \multicolumn{2}{|l|}{3.1447} & \\
\hline Intercept for $5^{\text {th }}$ group $(80-100 \%)$ & \multicolumn{2}{|l|}{3.9119} & \\
\hline \multicolumn{4}{|l|}{ Age-Period-Cohort } \\
\hline \multicolumn{4}{|c|}{ Age $($ reference category $=41-50$ years old $)$} \\
\hline $21-30$ & -0.4213 & * & 0.656 \\
\hline $31-40$ & -0.1780 & & 0.837 \\
\hline $51-60$ & -0.2073 & * & 0.813 \\
\hline $61-71$ & 0.1610 & & 1.175 \\
\hline \multicolumn{4}{|l|}{ Period $($ reference category $=2007)$} \\
\hline 2004 & 0.0379 & & 1.039 \\
\hline 2010 & -3.3233 & $* * *$ & 0.036 \\
\hline \multicolumn{4}{|c|}{ Cohort $($ reference category $=$ Baby boomer $)$} \\
\hline Silent generation & -0.2760 & & 0.759 \\
\hline $\mathrm{X}$ generation & 0.1840 & & 1.202 \\
\hline Y generation & -0.1814 & & 0.834 \\
\hline \multicolumn{4}{|l|}{ Demographic Characteristics } \\
\hline \multicolumn{4}{|c|}{ Household type (reference category $=$ Married female) } \\
\hline Married male & 0.9891 & $* * *$ & 2.689 \\
\hline Single male & 1.3882 & $* * *$ & 4.008 \\
\hline Single female & 0.9570 & $* * *$ & 2.604 \\
\hline Number of children & -0.0299 & & 0.971 \\
\hline \multicolumn{4}{|c|}{ Education (reference category $=$ High school diploma) } \\
\hline Less than high school diploma & 0.6584 & & 1.932 \\
\hline Some college & 0.4579 & ** & 1.581 \\
\hline Bachelor's degree & 0.7433 & $* * *$ & 2.103 \\
\hline Graduate or professional degree & 0.9412 & $* * *$ & 2.563 \\
\hline \multicolumn{4}{|c|}{ Race/Ethnicity (reference category $=$ White $)$} \\
\hline Black & 0.1356 & & 1.145 \\
\hline Hispanic & -0.1494 & & 0.861 \\
\hline Other & 0.4263 & ** & 1.532 \\
\hline \multicolumn{4}{|c|}{ Feature of Respondent's Pension Plans } \\
\hline Have DB plan(s) & -0.1533 & & 0.858 \\
\hline Have only one DC plan & -0.9186 & $* * *$ & 0.399 \\
\hline Allowed to borrow & 0.3197 & $* * *$ & 1.377 \\
\hline Allowed to withdraw & 0.4261 & $* *$ & 1.531 \\
\hline Employer's match & -0.7293 & $* * *$ & 0.482 \\
\hline Employer's match * year 2004 & 0.6923 & $* *$ & 1.998 \\
\hline Employer's match * year 2010 & 0.0106 & & 1.011 \\
\hline Job Tenure & -0.0013 & & 0.999 \\
\hline \multicolumn{4}{|l|}{ Economic Situations } \\
\hline \multicolumn{4}{|c|}{ Home ownership (reference category $=$ Own with loan) } \\
\hline Rent & -0.4599 & ** & 0.631 \\
\hline Own without loan & -0.5050 & $* * *$ & 0.604 \\
\hline Log (total income) & 3.8035 & $* * *$ & 44.858 \\
\hline \multicolumn{4}{|c|}{ Current income vs. normal income (reference category $=$ Lower than normal) } \\
\hline Equal normal & -0.3840 & ** & 0.681 \\
\hline Higher than normal & -0.4940 & $* *$ & 0.610 \\
\hline Log (net worth) & -0.7801 & & 0.458 \\
\hline
\end{tabular}


Risk tolerance (reference category $=$ Average risk)

No risk

Above average risk

$-0.3227 * \quad 0.724$

$0.3357 * * * \quad 1.399$

Substantial risk

$0.1244 \quad 1.132$

Expecting to receive large asset transfer in the future

$\begin{array}{ll}-0.0448 & 0.956\end{array}$

Expectation of future U.S. economy (reference category $=$ Worse)

About the same

Better

$-0.2407 * \quad 0.786$

$-0.2785 * * \quad 0.757$

$-0.1138 \quad 0.892$

Overspent

$0.1897 * \quad 1.209$

Retirement as a saving motive

$\begin{array}{lc}\text { Self-perceived retirement adequacy (reference category }=\text { Enough to maintain standard of living) } \\ \text { Total inadequate } & 0.0736\end{array}$

Inadequate $\quad-0.0471 \quad 0.954$

Between enough and very satisfactory $\quad 0.1699 \quad 1.185$

$\begin{array}{lll}\text { Very satisfactory } & 0.1972 & 1.218\end{array}$

Self-perceived health condition (reference category $=$ Good health)

Excellent health

$0.1919 * \quad 1.212$

Fair health

$-0.2117$

0.809

Poor health

0.2598

1.297

$* p<.05 ; * * p<.01 ; * * * p<.001$

Analysis of the 2004-2010 Survey of Consumer Finance; ordered logistic regression with weights; using RII technique; sample size $=3,502$. 
Figure 1. S\&P 500 Monthly Real Rates of Return during SCF Interview Periods

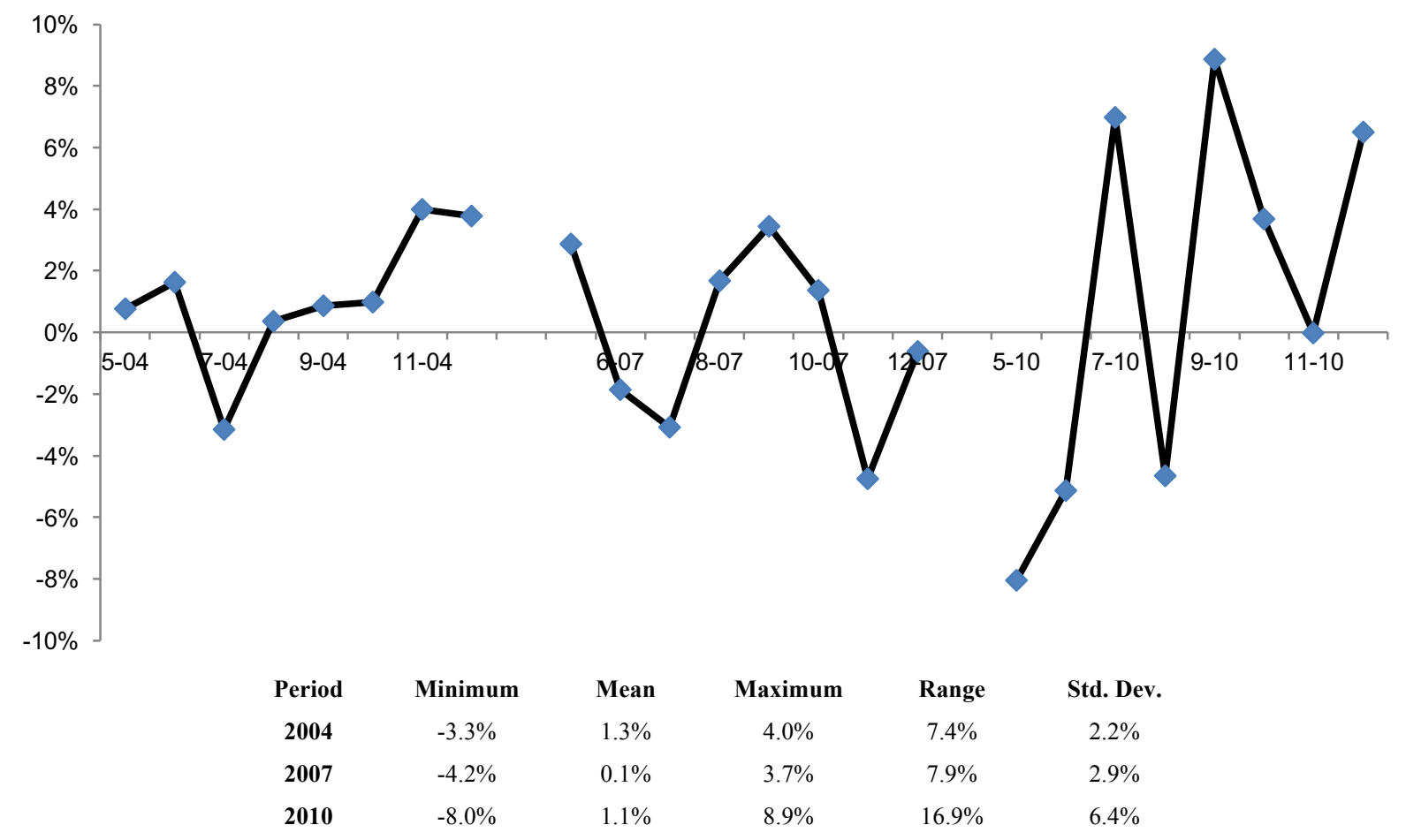

Note: S\&P 500 annual real rates of return calculated by authors using S\&P 500 annual nominal rates of return from Standard \& Poor's and CPI from the Bureau of Labor Statistics, during approximate interview months (May-December) in each survey year. 